\title{
Numerical simulation of RF catheter ablation for the treatment of arterial aneurysm
}

\author{
Xuemei Guo, Qun Nan* and Aike Qiao \\ College of Life Science and Bioengineering, Beijing University of Technology, Beijing, China
}

\begin{abstract}
Considering the blood coagulation induced by the heating of radio frequency ablation (RFA) and the mechanism of aneurysm embolization, we proposed that RFA may be used to treat arterial aneurysm. But the safety of this method should be investigated. A finite element method (FEM) was used to simulate temperature and pressure distribution in aneurysm with different electrode position, electric field intensity and ablation time. When the electrode is in the middle of the artery aneurysm sac, temperature rose clearly in half side of artery aneurysm, which is not suitable for RFA. Temperature rose in the whole aneurysm when the electrode is under the artery aneurysm orifice, which is suitable for the ablation therapy. And in this way, the highest temperature was $69.585^{\circ} \mathrm{C}$ when power was $5.0 \mathrm{~V} / \mathrm{mm}$ with $60 \mathrm{~s}$. It can promote the coagulation and thrombosis generation in the aneurysm sac while the outside tissue temperature rises a little. Meanwhile, the pressure (10 Pa) at the top of aneurysm sac with electrode insertion is less than that $(60 \mathrm{~Pa})$ without electrode, so electrode implant may protect the aneurysm from rupture. The results can provide a theoretical basis for interventional treatment of aneurysm with RFA.
\end{abstract}

Keywords: Radiofrequency ablation (RFA), arterial aneurysm, temperature distribution, finite element method (FEM)

\section{Introduction}

Aneurysms are common and dangerous diseases of cardiovascular and cerebrovascular which involves pathological dilation and weakening of the arteries [1]. Interventional treatment has become a hotspot to cure arterial aneurysm. The ultimate mechanism of interventional treatment is to diminish the blood flow in the aneurysm sac, promote the formation of intraluminal thrombus [2-5], shrink the aneurysm and avoid the aneurysm growing and rupture.

Interventional cardiovascular catheterization, such as stent and coiling are both of the advances to treat aneurysms [6-8], should stay in the body and have some complications, such as the displacement of the stent and the coil fall off from the aneurysm $[9,10]$. Considering the blood coagulation induced by the heating of radiofrequency ablation (RFA), the mechanism of aneurysm embolization and the advantages of simple operation, small trauma, low cost, faster recovery, high success rate, etc [11-15], Qiao, et al proposed that RFA may be used to treat aneurysm by combining the mechanism of blood coagulation of RFA and aneurysm embolization [16]. The initiation of this hypothesis is to overcome the disadvantages of biological/mechanical mismatch between the interventional devices and the

\footnotetext{
* Address for correspondence: Qun Nan, College of Life Science and Bioengineering, Beijing University of Technology, Beijing, China. Tel.: 010-67392855; Fax: 010-67392855; E-mail: nanqun@bjut.edu.cn.
} 
arteries in the interventional therapy, also utilize the advantages of rapid treatment and minimal invasion in the thermal ablation procedure.

The present study aims to explore the key problems for treating aneurysm by RFA, such as the influence of the electrode position, RF power and ablation time to the temperature distribution. Two different positions of electrode, three different electric field intensity and ablation times were also investigated to determine the temperature distribution and the pressure. The results can provide a theoretical basis for interventional treatment of aneurysm with RFA.

\section{Materials and methods}

\subsection{Model}

The idealized 2D models of aneurysm treated with FRA are shown in Figure 1, including the artery, the aneurysm, the blood and the RF electrode: one is under the aneurysm orifice (Model I), the other is in the middle of the aneurysm sac (Model II). They were created by Comsol Multiphysics (Comsol, Sweden) which applies finite element method by solving partial differential equations (single field and multi-field) to achieve the numerical results. The thermal and electrical parameters of the blood, vessel wall and outside tissues were added to the related materials (as shown in Table 1). As shown in Figure 1(a), three different points A (at the top of aneurysm), B (in the downstream near the electrode) and C (in the downstream away from the electrode) were chosen to analyze the pressure.

In order to simplified calculation, the blood flow was regard as laminar flow. And only the length of the vessel both in proximal and distal of the aneurysm was more than tenfold of the aneurysm radius, the blood can be fully flowed. The inlet of the blood flow was set at the side of electrode with the constant entrance velocity $0.38 \mathrm{~m} / \mathrm{s}$ [21]. The pressure at the exit was set to $0 \mathrm{~Pa}$. The electric field intensity was applied on the top of the electrode. The initial temperature was set to $37^{\circ} \mathrm{C}$.

The model was discretized with more than 20 million meshes. Mesh refinement was adopted near the electrode and the arterial aneurysm. Mesh independence analysis was accomplished to affirm the accuracy and reliability of the simulation results for ablation processes.

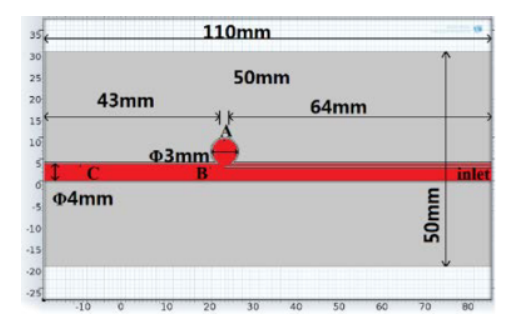

(a) Model I

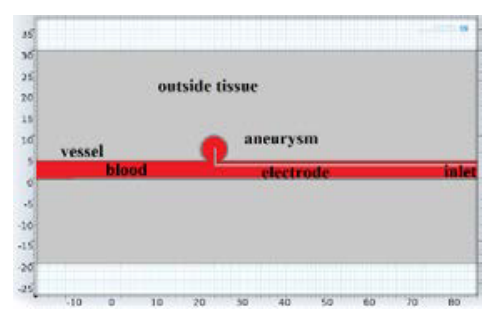

(b) Model II

Fig. 1. Arterial aneurysm model.

Table 1

The thermal and electrical parameters [17-20]

\begin{tabular}{lllll}
\hline & $\rho\left(\mathrm{kg} / \mathrm{m}^{3}\right)$ & $k\left(\mathrm{~W} / \mathrm{m} \cdot{ }^{\circ} \mathrm{C}\right)$ & $\sigma(\mathrm{s} / \mathrm{m})$ & $c\left(\mathrm{~J} / \mathrm{kg} \cdot{ }^{\circ} \mathrm{C}\right)$ \\
\hline Vessel wall & 1150 & 0.48 & 0.50 & 3200 \\
Blood & 1000 & 0.543 & 0.99 & 4180 \\
Tissue & 1060 & 0.55 & 1.00 & 3600 \\
\hline
\end{tabular}




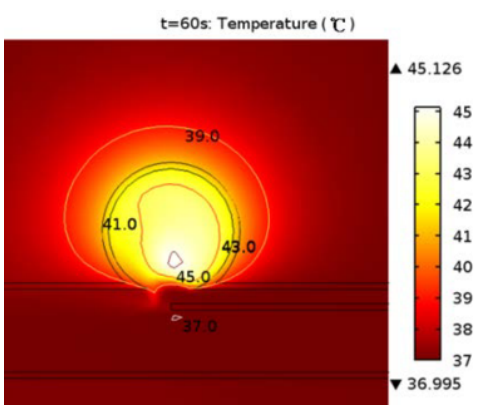

(a) $2.5 \mathrm{~V} / \mathrm{mm}$

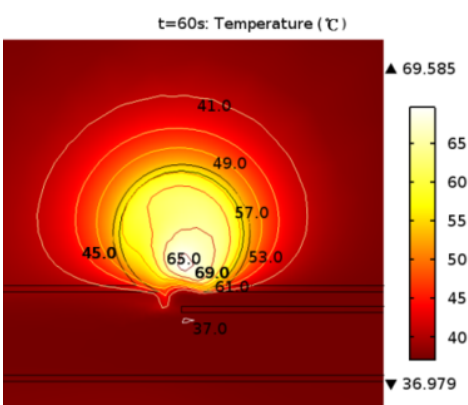

(b) $5 \mathrm{~V} / \mathrm{mm}$

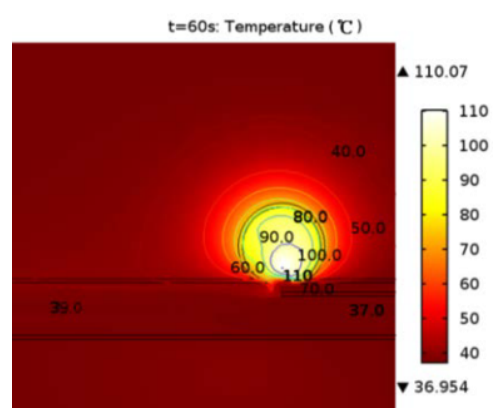

(c) $7.5 \mathrm{~V} / \mathrm{mm}$

Fig. 2. Arterial aneurysm temperature distribution with different electric field intensity (Model I).

\subsection{Bio-heat equation}

The temperature distribution in the arterial aneurysm model was obtained by solving the bio-heat equation $[17,22]$.

$$
\rho c \frac{\partial \mathrm{T}}{\partial \mathrm{t}}=k \nabla^{2} T+\omega_{b} c_{b}\left(T_{b}-\mathrm{T}\right)+Q_{m}+Q_{r}
$$

where $\rho$ is tissue density $\left(\mathrm{kg} / \mathrm{m}^{3}\right), \mathrm{k}$ is the thermal conductivity of tissue $\left(\mathrm{W} / \mathrm{m} \cdot{ }^{\circ} \mathrm{C}\right), \mathrm{c}$ and $\mathrm{c}_{\mathrm{b}}$ is specific heat of tissue and blood $\left(\mathrm{J} / \mathrm{kg} \cdot{ }^{\circ} \mathrm{C}\right), \omega_{b}$ is the mass flow rate of blood per unit volume of tissue $\left(\mathrm{kg} / \mathrm{s} \cdot \mathrm{m}^{3}\right), T$ and $\mathrm{T}_{\mathrm{b}}$ is the temperature of tissue and blood, $\mathrm{Q}_{\mathrm{m}}$ is the heat generated by metabolism, and $\mathrm{Q}_{\mathrm{r}}$ is the heat generated by $\mathrm{RF}\left(\mathrm{W} / \mathrm{m}^{3}\right)$. The heat generated by metabolism and taken away by blood perfusion was ignored in this research compared with high power of RF.

\section{Results and discussion}

\subsection{The effect of electric field intensity on the temperature field distribution}

Figure 2 shows the temperature distribution of Model I with the ablation time $60 \mathrm{~s}$ when the electric field intensity is $2.5 \mathrm{~V} / \mathrm{mm}, 5 \mathrm{~V} / \mathrm{mm}$ and $7.5 \mathrm{~V} / \mathrm{mm}$ respectively. The highest temperatures is correspondingly $45.126^{\circ} \mathrm{C}, 69.585^{\circ} \mathrm{C}$ and $110.07^{\circ} \mathrm{C}$, respectively. The temperature field distribution appears approximately as a circle which fills the whole arterial aneurysm sac. The temperature of the blood and other side is hardly risen except at the side of the aneurysm sac, the outside tissue near the arterial aneurysm sac wall has risen about $3{ }^{\circ} \mathrm{C}, 13^{\circ} \mathrm{C}$ and $43^{\circ} \mathrm{C}$, respectively. The blood temperature in the downstream is a little higher $\left(1^{\circ} \mathrm{C}\right)$ than the upstream at $7.5 \mathrm{~V} / \mathrm{mm}$.

With the increase of the electric field intensity, the lesion range and the temperature in the outside tissue increase. Under the same ablation time, the highest temperature rises about $24^{\circ} \mathrm{C}$ with the increase of the electric field intensity from $2.5 \mathrm{~V} / \mathrm{mm}$ to $5 \mathrm{~V} / \mathrm{mm}$, while the highest temperature rises nearly $40^{\circ} \mathrm{C}$ with the increase of the electric field intensity from $5 \mathrm{~V} / \mathrm{mm}$ to $7.5 \mathrm{~V} / \mathrm{mm}$.

The temperature distribution of Model II is shown in Figure 3. The highest temperatures are correspondingly $39.39^{\circ} \mathrm{C}, 46.56^{\circ} \mathrm{C}$ and $58.45^{\circ} \mathrm{C}$ respectively when the electric field intensity is 2.5 $\mathrm{V} / \mathrm{mm}, 5 \mathrm{~V} / \mathrm{mm}$ and $7.5 \mathrm{~V} / \mathrm{mm}$ respectively with the ablation time $60 \mathrm{~s}$. The arterial aneurysm temperature rises clearly in the left half of arterial aneurysm sac. The temperature of the outside tissue 


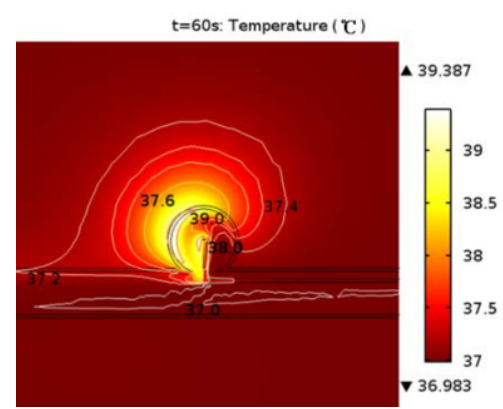

(a) $2.5 \mathrm{~V} / \mathrm{mm}$

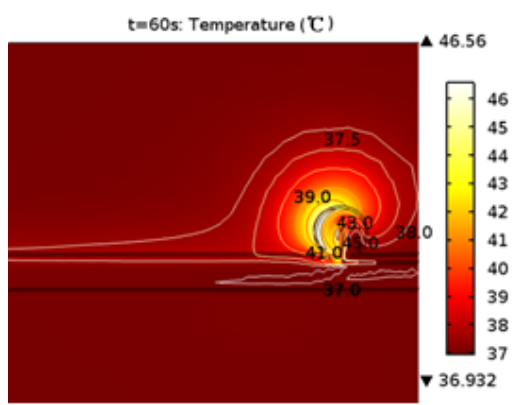

(b) $5 \mathrm{~V} / \mathrm{mm}$

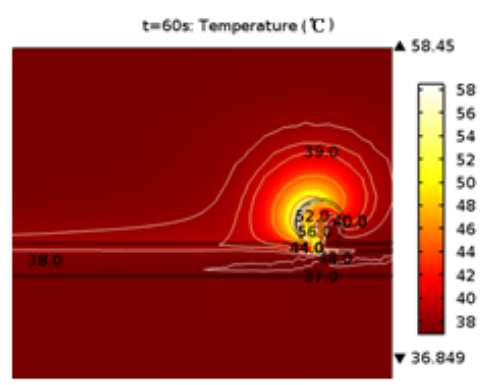

(c) $7.5 \mathrm{~V} / \mathrm{mm}$

Fig. 3. Arterial aneurysm temperature distribution with different electric field intensity (Model II).

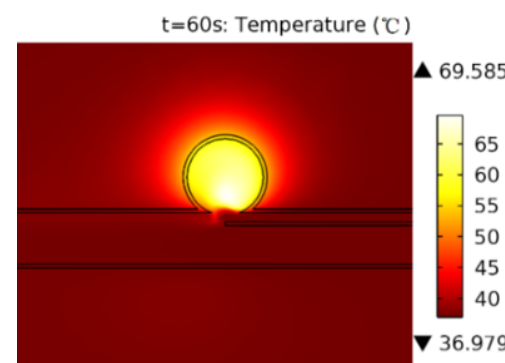

(a) $60 \mathrm{~s}$

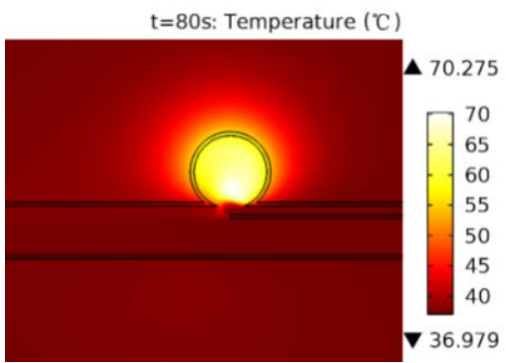

(b) $80 \mathrm{~s}$

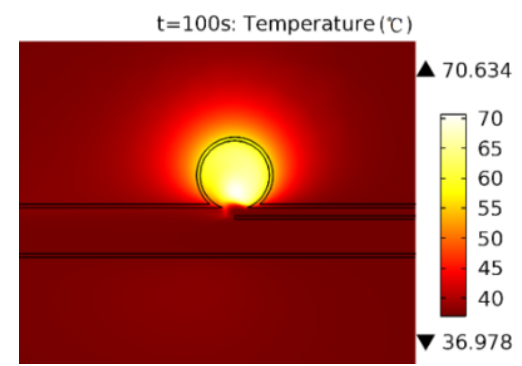

(c) $100 \mathrm{~s}$

Fig. 4. Arterial aneurysm temperature distribution with different ablation time (Model I).

and vessel also had a temperature rise in a small range.

Because of the blood flow, the temperature in the right side has hardly risen, and the blood temperature in the downstream is a little higher (about $0.2^{\circ} \mathrm{C}, 0.5^{\circ} \mathrm{C}, 1^{\circ} \mathrm{C}$ ) than the upstream, especially at $5 \mathrm{~V} / \mathrm{mm}$ and $7.5 \mathrm{~V} / \mathrm{mm}$. Under the same ablation time, the highest temperature rise about $7^{\circ} \mathrm{C}$ with the increase of the electric field intensity from $2.5 \mathrm{~V} / \mathrm{mm}$ to $5 \mathrm{~V} / \mathrm{mm}$, while the highest temperature rise nearly $12^{\circ} \mathrm{C}$ with the increase of the electric field intensity from $5 \mathrm{~V} / \mathrm{mm}$ to $7.5 \mathrm{~V} / \mathrm{mm}$.

\subsection{The influence of ablation time on the distribution of the temperature field}

As shown in Figure 4, the ablation time is $60 \mathrm{~s}, 80 \mathrm{~s}$ and $100 \mathrm{~s}$, respectively. The highest temperature is $69.59^{\circ} \mathrm{C}, 70.26^{\circ} \mathrm{C}$ and $70.63^{\circ} \mathrm{C}$ respectively. According to the temperature distribution the temperature increase a little (less than $1^{\circ} \mathrm{C}$ ) with the increasing of ablation time. As shown in

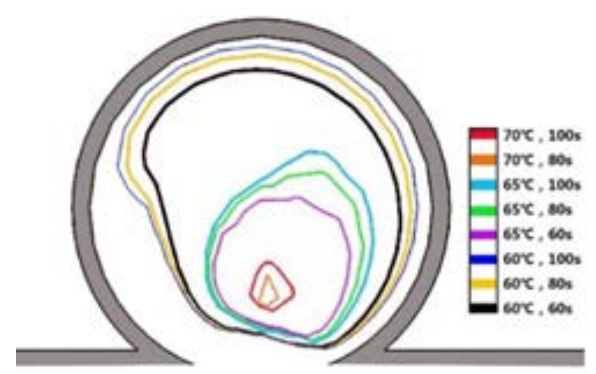

Fig. 5. Arterial aneurysm temperature isothermal contour with different ablation time ( $60 \mathrm{~s}, 80 \mathrm{~s}, 100 \mathrm{~s})$. 


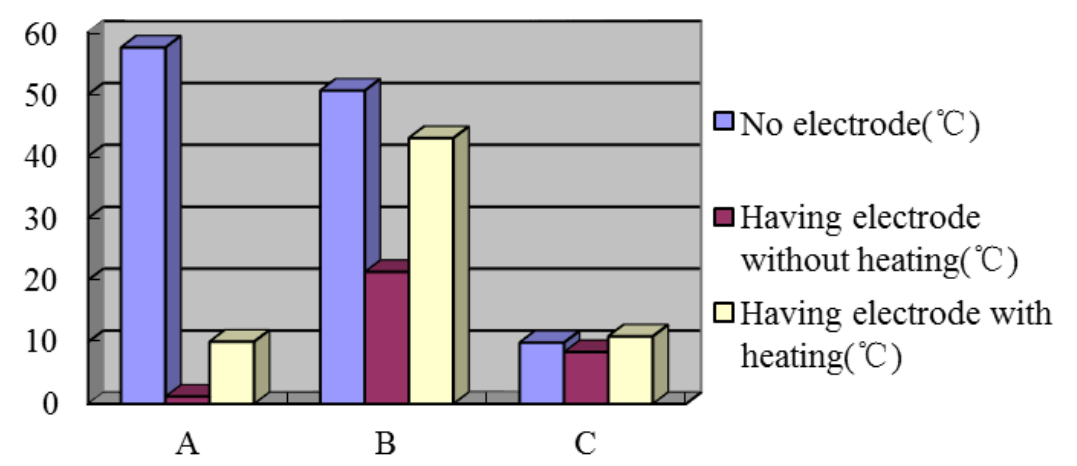

Fig. 6. Pressure comparison charts (Model I).

Figure 5, the isothermal contour has the similar shape and expands with the increase of ablation time.

\subsection{The distribution of blood pressure}

The rising of the pressure can make the arterial aneurysm rupture, so the change of the pressure after the electrode implanted is very important [23]. To study the effects of radiofrequency ablation on the pressure, pressures at some specific points are analyzed (Figure 1(a)). Under different conditions (one without electrode, one with electrode but without heating, and the other with electrode with heating), the pressure at points A, B and C are shown in Figure 6.

The pressure in the above three points would reduce with the implantation of electrode, and the reduced magnitudes are about $57 \mathrm{~Pa}, 28 \mathrm{~Pa}$ and $3 \mathrm{~Pa}$ at point $\mathrm{A}, \mathrm{B}$ and $\mathrm{C}$ respectively. When heating with the electrode, the pressure would rise about $10 \mathrm{~Pa}, 20 \mathrm{~Pa}$ and $4 \mathrm{~Pa}$ at point $\mathrm{A}, \mathrm{B}$ and $\mathrm{C}$ respectively. The heating makes the pressure rise, but the pressure both at point $\mathrm{A}$ and $\mathrm{B}$ is still lower than that without electrode. The pressure of point $\mathrm{C}$ with heating is only about $2 \mathrm{~Pa}$ higher than that without electrode. It has little effect on the vessel. The pressure at the top of the aneurysm is the highest and it is the most important factor which can make the arterial aneurysm rupture, but the implantation of electrode makes the pressure reduce and may protect the aneurysm from rupture.

\section{Discussions and conclusions}

Due to the blood flow, the temperature in the main blood flow is hardly risen in the both model. In Model I, the temperature rises in the whole aneurysm, while temperature rises only in left half side of the aneurysm in Model II. The goal is to diminish blood flow in aneurysm sac and promote coagulation and thrombosis generation. From Figures 2 and 3, model I (electrode under the arterial aneurysm orifice) is more suitable to aneurysm ablation.

Temperature increases with both the increasing of electric field intensity and ablation time, the temperature increase is more than $7^{\circ} \mathrm{C}$ with every additional electric field intensity $2.5 \mathrm{~V} / \mathrm{mm}$ while the temperature increase is less than $1{ }^{\circ} \mathrm{C}$ with every additional ablation time $20 \mathrm{~s}$. The influence of the electric field intensity is much more significant than the ablation time. When the electrode is under the aneurysm orifice (Model I), with the electric field intensity $5 \mathrm{~V} / \mathrm{mm}$ and the ablation time $60 \mathrm{~s}$, the temperature field is filled in the whole aneurysm sac which can promote the coagulation and thrombosis generation in the aneurysm sac [24] while the outside tissue temperature rises a little, so it 
is more suitable for aneurysm ablation. In this particular case, arterial aneurysm can be treated with the method of interventional ablation procedures.

Aneurysm rupture is the serious complications in treatment aneurysm which may lead the death of the patient. The implantation of electrode or stent may change the pressure distribution in the arterial aneurysm. As shown in Figure 6, the pressure in the three points would reduce with the implantation of electrode. The pressure with electrode at point A and B is lower than that without electrode which may protect the aneurysm from rupture. And study also shows that the implantation of stent can lead to the weakening of pressure, especially in the top of the aneurysm [25]. When heating the pressure of point $\mathrm{C}$ is only about $2 \mathrm{~Pa}$ higher than that without electrode and hence has little effect on the vessel.

Both of the above two factors, $5 \mathrm{~V} / \mathrm{mm}$ and $60 \mathrm{~s}$ heating time are the optimum parameters of RFA for treatment of arterial aneurysm.

However, due to the shortage of clinical data, an idealized model was taken into account. Accurate data will be connected from clinicians to perfect our simulation in the future. The velocity may have greater effect on the temperature field when 3D models were considered. Ex vivo experiment will be done to verify the correctness of the simulation. By studying the hemodynamics and the influence of temperature field, a hypothesis of curing the arterial aneurysms with little hemodynamic change will be put forward.

\section{Acknowledgments}

This research is supported by National Science Foundation of China (No. 31070754), Beijing Municipal Commission of Education Project Scientific and Technological Program (KM201410005028), the Importation and Development of High-Caliber Talents Project of Beijing Municipal Institutions for three years (Nan Qun) and Basic Research Foundation of Beijing University of Technology (X4015999201401). The author thanks Prof. Qiao for his favorable advice and kind guidance.

\section{References}

[1] C. Shi, M. Kojima, C. Tercero, et al., A cyber-physical system for strain measurements in the cerebral aneurysm models, 2012 IEEE/RSJ International Conference on Intelligent Robots and Systems, Vilamoura, 2012, pp. 4137-4142.

[2] A.K. Wakhloo, G. Lanzino, B.B. Lieber, et al., Stents for intracranial aneurysms: the beginning of a new endovascular era, Neurosurgery 43 (1998), 377-379.

[3] B.B. Lieber, A.P. Stancampiano and A.K. Wakhloo, Alteration of hemodynamics in aneurysm models by stenting: Influence of stent porosity, Annals of Biomedical Engineering 25 (1997), 460-469.

[4] W. Fu, Z. Gu, X. Meng, et al., Numerical simulation of hemodynamics in stented internal carotid aneurysm based on patient-specific model, Journal of Biomechanics 43 (2010), 1337-1342.

[5] Y.S. Zhang, X.J. Yang, S.Z. Wang, et al., Hemodynamic effects of stenting on wide-necked intracranial aneurysms, Chinese Medical Journal 123 (2010), 1999-2003.

[6] G.K. Wong, M.C. Kwan, R.Y. Ng, et al., Flow diverters for treatment of intracranial aneurysms: Current status and ongoing clinical trials, Journal of Clinical Neuroscience 18 (2011), 737-740.

[7] M.J. Binning, S.K. Natarajan, K.R. Bulsara, et al., Silk flow-diverting device for intracranial aneurysms, World Neurosurgery 76 (2011), 401-404.

[8] L. Pierot, Flow diverter stents in the treatment of intracranial aneurysms: Where are we? Journal of Neuroradiology 38 (2011), 40-46.

[9] I. Szikora, Z. Berentei, Z. Kulcsar, et al., Treatment of intracranial aneurysms by functional reconstruction of the parent artery: The Budapest experience with the Pipeline embolization device, American Journal of Neuroradiology 31 (2010), $1139-1147$. 
[10] D.S. Molony, E.G. Kavanagh, P. Madhavan, et al., A computational study of the magnitude and direction of migration forces in patient-specific abdominal aortic aneurysm stent-grafts, European Journal of Vascular \& Endovascular Surgery the Official Journal of the European Society for Vascular Surgery 40 (2010), 332-339.

[11] R. Lencioni, L. Crocetti, M.C.D. Pina, et al., Percutaneous image-guided radiofrequency ablation of liver tumors, Abdom Imaging 34 (2009), 547-556.

[12] A. Veltri, M. Grosso, F. Castagneri, et al., Radiofrequency thermal ablation of small tumors in transplanted kidneys: An evolving nephron-sparing option, Journal of Vascular \& Interventional Radiology 20 (2009), 674-679.

[13] J.R. Garbay, M.C. Mathieu, M. Lamuraglia, et al., Radiofrequency thermal ablation of breast cancer local recurrence: A phase II clinical trial, Annals of Surgical Oncology 15 (2008), 3222-3226.

[14] R. Zhang, H. Liu and H. Li, Finite element analysis of radiofrequency ablation process in soft tissue sarcomas, 2014 4th IEEE International Conference on Information Science and Technology, Shenzhen, 2014, pp. 358-363.

[15] Y. Isobe, H. Watanabe, N. Yamazaki, et al., Real-time temperature control system based on the finite element method for liver radiofrequency ablation: Effect of the time interval on control, 2013 35th Annual International Conference of the IEEE on Engineering in Medicine and Biology Society, Osaka, 2013, pp. 392-396.

[16] A. Qiao, Q. Nan, Y. Liu, et al., Can interventional ablation be applied to the treatment of arterial aneurysm? Medical Hypotheses 80 (2013), 373-375.

[17] E.J. Berjano and F. Hornero, Thermal-electrical modeling for epicardial atrial radiofrequency ablation, IEEE Transactions on Biomedical Engineering 51 (2004), 1348-1357.

[18] P. Liu, J. Liu and H. Duan, Finite element modeling simulation of cardiac radiofrequency catheter ablation based on heart chamber anatomy, Chinese Journal of Biomedical Engineering 31 (2012), 352-358.

[19] P. Bernardi, M. Cavagnaro and J.C. Lin, Distribution of SAR and temperature elevation induced in a phantom by a microwave cardiac ablation catheter, IEEE Transactions on Microwave Theory \& Techniques 52 (2004), 1978-1986.

[20] X. Guo, F. Zhai and Q. Nan, The temperature field simulation of radiofrequency catheter-based renal sympathetic denervation for resistant hypertension, Bio-Medical Materials and Engineering 24 (2014), 315-321.

[21] W. Meng, J. Qian, X. Shen, et al., Assessment of coronary hemodynamics with Doppler wire after coronary balloon angioplasty and intracoronary stenting, Chinese Journal of Cardiology 27 (1999), 335-339.

[22] M.K. Jain and P.D. Wolf, Temperature controlled and constant power radiofrequency ablation: What's affects lesion growth? IEEE Transaction on Biomedical Engineering 46 (1999), 1405-1412.

[23] A.K.N. Lam, M.W.L. Ko, L.K.K. Leung, et al., Characterization of pressure reduction in coil-filled aneurysm under flow of human blood with and without anti-coagulant, 2013 35th Annual International Conference of the IEEE on Engineering in Medicine and Biology Society, Osaka, 2013, pp. 739-742.

[24] L. Chen, Z. Zhang, G. Zeng, et al., Saline-irrigated versus standard radiofrequency catheter ablation for idiopathic ventricular tachycardia, Chinese Journal of Cardiac Pacing and Electrophysiology 23 (2009), 40-42.

[25] A. Qiao, Y. Liu and S. Zhang, simulation of stent treatment for aneurysms in the inner bend of aortic arch, Sheng Wu Yi Xue Gong Cheng Xue Za Zhi 24 (2007), 852-856. 